\title{
Time Allocation, Consumption, and Consumer Policy
}

\author{
Wencke Gwozdz • Lucia A. Reisch • Alfonso Sousa-Poza
}

Published online: 23 March 2010

(C) Springer Science+Business Media, LLC. 2010

It can be argued that the fundamental scarce resource in the economy is the availability of human time.

(Juster and Stafford 1991, p. 471).

Although time may indeed be the most important of economic resources, it was not until Gary Becker's (1964) seminal paper that a serious attempt was made to develop a theoretical framework that could analyse the way in which individuals allocate their time between various activities. This is not to say that traditional economic theory totally ignored this topic; rather, time took on a very secondary role. In subsequent decades, however, economic, psychological and sociological investigators have all devoted considerable energy to developing models and collecting data on time use. Nevertheless, despite the large body of time-use literature that has evolved over the past decades, one aspect has still received relatively little attention: the effect of changes in time-use behaviour in general and increased time pressure in particular (see, e.g., Linder 1970; Roxburgh 2002) has had on consumers and how consumer policy has reacted to these developments.

Individual consumption and time use can be viewed from several perspectives: as the process of using - or enjoying or even dissipating - personal goods and services; as the effort to acquire personal wealth, which usually means engaging in paid work and balancing it with the needs of (unpaid) work in the informal sector (e.g., care giving, household work); and/or as the handling, disposing, and managing of the accumulated "stuff of life." From all perspectives, consumption is deeply embedded in the context of social "time scapes" (Adam 1998) that, by defining its hours, rhythms, and temporalities, shape and restrict consumer decisions in myriad ways. Hence, recognition of the growing

W. Gwozdz $(\bowtie) \cdot$ L. A. Reisch

Department of Intercultural Communication and Management, Copenhagen Business School, Porcelænshaven 18A, 2000 Frederiksberg, Denmark

e-mail: wg.ikl@cbs.dk

A. Sousa-Poza

Institute of Household and Consumer Economics, University of Hohenheim, Fruwirthstrasse 48, 70599

Stuttgart, Germany 
impact of this time factor on consumption has brought forth a discussion of explicit "time policies" as integral part of consumer policy (Reisch 2001).

The purpose of this special issue is to highlight particular topics related to time-use and consumer policy, which for practicality are grouped into three classifications: market (paid or "formal") work, household (unpaid or "informal") work, and leisure (see, e.g., Winston 1982).

Although the changes in all three categories over the past decades have been large, leisure time particularly has increased substantially (Ghez and Becker 1975; Juster and Stafford 1985; Robinson and Godbey 1999). For example, Aguiar and Hurst (2007) show that, in the United States, leisure for men has increased by roughly 6 to $9 \mathrm{~h}$ per week and for women by around 4 to $8 \mathrm{~h}$ per week. In general, their analysis also reveals a growing inequality in leisure that mirrors the growing inequality in wages and expenditures. They therefore conclude that welfare calculations based solely on wages and expenditures are incomplete.

Because time use is a zero-sum game (i.e., increases in one time-allocation category inevitably reduce time spent in another), this increase in leisure must be compensated by reductions in other time-use categories. Hence, to some extent, and especially for men, increases in leisure have gone hand-in-hand with a reduction in market work. For instance, Costa (2000) shows that over the last century, low-wage workers especially have dramatically decreased their market work hours relative to high-wage workers. In the case of women, rises in leisure time have been partially met by decreases in household work time. Nevertheless, these changes deviate quite substantially from country to country. For example, market work hours in Europe differ notably from those in the United States: Americans work longer hours than Europeans. According to Freeman and Schettkat (2005), this difference is attributable to greater marketisation in the US of traditional household production.

Nor is it only the absolute number of hours allocated to each time category that has changed; the nature of these categories has also become very different. Most notable is the well-documented increase in working time flexibility, including flexible work schedules, working on-call, parental leave and other long-term leave arrangements, and part-time work, as well as early and phased retirement (Chung et al. 2007). This increased flexibility has strongly influenced not only when leisure time and household work time are performed but also how and where.

Because such changes in time allocation have significant policy implications, especially for consumers, each of the four papers in this special issue focuses on one specific timeallocation category. The first addresses one of the most straightforward links between timeallocation research and consumer policy, the time spent on daily shopping activities. This time allocation is important not only because, by combining bought market goods with time, it allows what Becker (1964) terms the production of commodities, but because the allocation of time to shopping activities is strongly determined by public regulations (most notably, shopping times). Moreover, as Joachim Merz, Dominik Hanglberger, and Rafael Rucha (2010) point out, although marketing research and the empirical literature on the consumer includes a wide range of studies on the demand for goods, there are few empirical studies on the timing of consumption. They therefore draw on the 2001/2002 German Time Budget Survey dataset to examine in detail the timing of the daily demand for goods and services in Germany and make predictions about how this timing will change in future, particularly in light of demographic changes and increased labour-market flexibility. One of their most striking results is that demographic and labour-market developments will probably give rise to an increased demand for goods and services in the morning - a result 
probably not expected by German policy makers when they liberalized opening hours to allow evening shopping. Hence, this study shows not only how time-use categories are interlinked but also how labour-market policies and developments affect changes in time allocation within households.

The second paper, by Steffen Otterbach (2010), goes a step further by investigating whydespite the greater expansion of flexible working hours documented in Merz et al. (2010) - a large portion of the workforce is unhappy with its working time. More specifically, it examines an important and often puzzling phenomenon: the working hour constraints that arise when desired and actual working times fail to coincide and lead to sub-optimal time allocation. From a theoretical perspective, explaining why (in a market economy) such constraints arise has been quite difficult, and no single convincing argument for this phenomenon yet exists (see, e.g., Lang and Kahn 2001). Otterbach (2010) analyses the ISSP survey, an interesting multi-national dataset, which shows the extent and dynamics of hours constraints in 21 countries. His analysis reveals not only that both over- and underemployment are widespread and persistent, but that hours constraints depend on myriad factors, including a range of macroeconomic variables like unemployment rates, GDP per capita, and even income inequality. Underemployment, especially, is very pronounced (even in the United States) and in some countries (such as Germany) is even increasing. According to Otterbach (2010), this finding can be primarily attributed to rising poverty and income inequality, implying that policy measures to combat poverty can also effectively combat underemployment. He further argues that hours constraints can best be reduced by consumer policies that increase the availability of part-time jobs and provide a better balance between work and family life.

In general, despite the average reduction in working time over the past decades, a large portion of society is underemployed, and despite the increase in leisure that accompanies this working time reduction, there appears to be a well-documented rise in time pressure (Robinson and Godbey 1999). To address this somewhat paradoxical situation, Ilse Laurijssen, Joeri Minnen and Theun Pieter van Tienoven (2010) focus on the "harried leisure class," which uses its more abundant income to expand pleasure and consumption and its "equanimous" counterpart, which consumes leisure more passively and thus experiences less time pressure. They define the first by quoting Linder's (1970) succinct description: "[...] the average earner in the rich country lives nonetheless under the pressure of time. He is a member of the harried leisure class. [...] We will find [...] an infinite volume of consumption goods, which pleasure-hungry angels will feverishly try to exploit during the limited time at their disposal per day" (p. 13). Using data from the pooled Flemish timeuse survey of 1999 and 2004, these authors clearly identify these two different leisure classes and show that the harried leisure class indeed experiences time pressure and engages in voracious and volatile leisure time consumption, whereas the members of the equanimous leisure class primarily consume their leisure time watching television. Their study therefore highlights both the different forms that leisure can take and the different types of leisure activities demanded. As the authors point out, despite its hastiness, the harried leisure class produces a significant demand for goods that can be consumed in short time slots.

The final paper in this special issue addresses the important time-allocation category of "housework time," unpaid yet productive work that, in contrast to the significant attention paid in many academic disciplines to leisure and market work, has gone largely unnoticed (Shelton 1992). Yet, in many countries, more time is spent on housework than on paid employment, leaving the importance and value of such work undisputed. Hence, using data from the 2001/2002 and 1991/1992 German Time Use Survey, Wencke Gwozdz and 
Alfonso Sousa-Poza (2010) address the ubiquitous gender bias in time spent on housework. They show that, although in the past decade women have reduced the time they devote to housework, the unequal division of housework between men and women persists. Among other factors, this decline in time spent on housework can be partially attributed to the greater marketisation of traditional household production; that is, as noted for the United States (Freeman and Schettkat 2005), it is being driven by increases in wages and an aspiration for market goods consumption. This diminishing importance of housework time and the increased relevance of market substitutes have important policy implications for consumers, including the availability and quality of (public) childcare facilities and the property and quality of convenient foods.

Needless to say, four essays on four different time-use categories can only offer rudimentary insight into the many topics associated with time-allocation and consumer policies. Nevertheless, we hope that this special issue brings to the fore the important implications of time-use investigations for consumer research and consumer policies - an intersection that, in our opinion, has not received the attention it deserves.

\section{References}

Adam, B. (1998). Timescapes of modernity: The environment and invisible hazards. New York: Routledge. Aguiar, M., \& Hurst, E. (2007). Measuring trends in leisure. Quarterly Journal of Economics, 122(3), 9691006.

Becker, G. S. (1964). Human capital: A theoretical and empirical analysis with special reference to education. New York: Columbia University Press.

Chung, H., Kerkhofs, M., \& Ester, P. (2007). Working time flexibility in European companies. Dublin: European Foundation.

Costa, D. (2000). The wage and the length of the work day: From the 1890s to 1991. Journal of Labor Economics, 18, 156-181.

Freeman, R., \& Schettkat, R. (2005). Marketization of household production and the EU-US gap in work. Economic Policy, 20(41), 6-50.

Ghez, G., \& Becker, G. (1975). The allocation of time and goods over the life cycle. New York: Columbia University Press.

Glorieux, I., Laurijssen, I., Minnen, J., \& van Tienoven, T. P. (2010). In search of the harried leisure class in contemporary society: time-use surveys and patterns of leisure time consumption. Journal of Consumer Policy, this issue.

Gwozdz, W., \& Sousa-Poza, A. (2010). Explaining gender differences in housework time in Germany. Journal of Consumer Policy, this issue.

Juster, T., \& Stafford, F. (1985). Time goods and well-being. Ann Arbor: University of Michigan Press.

Lang, K., \& Kahn, S. (2001). Hours constraints. In G. Wong \& G. Picot (Eds.), Working time in comparative perspective (Vol. 1, pp. 261-287). Kalamazoo: W.E. Upjohn Institute for Employment Research.

Linder, S. B. (1970). The harried leisure class. New York: Columbia University Press.

Merz, J., Hanglberger, D., \& Rucha, R. (2010). The timing of daily demand for goods and servicesmicrosimulation policy results of an aging society, increasing labour market flexibility and extended public childcare in Germany. Journal of Consumer Policy, this issue.

Otterbach, S. (2010). Mismatches between actual and preferred work time: Empirical evidence of hours constraints in 21 countries. Journal of Consumer Policy, this issue.

Reisch, L. (2001). Time and wealth. The role of time and temporalities for sustainable patterns of consumption. Time \& Society, 10(2/3), 367-385.

Robinson, J., \& Godbey, G. (1999). Time for life (2nd ed.). University Park: Pennsylvania State University Press.

Roxburgh, S. (2002). Racing through life: The distribution of time pressures by roles and role resources among full-time workers. Journal of Family and Economic Issues, 23, 121-145.

Shelton, B. A. (1992). Women, men and time: Gender differences in paid work, housework and leisure. New York: Greenwood Press.

Winston, G. C. (1982). The timing of economic activities: Firms, households, and markets in time-specific analysis. Cambridge: Cambridge University Press. 